\title{
A gestão da Central de Abastecimento de Goiás (CEASA-GO): seus números e propostas de melhorias
}

\author{
Karla Kellem de Lima ${ }^{1}$ \\ Altivo Roberto Andrade de Almeida Cunha ${ }^{2}$ \\ Antonio Pasqualetto ${ }^{3}$ \\ Taric Calii ${ }^{4}$ \\ Sérgio Duarte de Castro ${ }^{5}$
}

\begin{abstract}
Resumo
A atividade fragmentada e informal do mercado de hortigranjeiro levou à discussão, no final dos anos 1950, sobre a criação de Centrais de Abastecimento Alimentar (CEASA) no Brasil. O objetivo central deste estudo é compreender a inserção da CEASA de Goiás no mercado nacional e identificar melhorias à gestão da instituição. Realizou-se uma pesquisa descritiva em manuais operacionais das Ceasas do Brasil, em artigos da época do Sistema Nacional de Centrais de Abastecimento (SINAC), pelo Ministério da Agricultura, Pecuária e Abastecimento em conjunto com a Companhia Nacional de Abastecimento (CONAB). Metodologicamente, classificou-se a pesquisa em exploratória, descritiva, bibliográfica, documental e de campo, tendo como objeto de estudo a CEASA-GO e, como instrumento de coleta de dados, um questionário aplicado aos agentes públicos e privados desta Central. Os resultados demonstram que a Central de Abastecimento de Goiás teve um enorme crescimento ao longo do tempo. Tal crescimento elevou significativamente o número de empresas, trabalhadores e usuários da instituição, o que acarreta cada vez mais demandas. Aliado a isso, as exigências de um modelo de gestão mais sustentável dos pontos de vista social e ambiental requerem mudanças que priorizem o meio ambiente e a sociedade como um todo.
\end{abstract}

Palavras-Chave: Ceasa. Goiás. Gestão. Hortigranjeiros.

\begin{abstract}
The fragmented and informal activity horticulture market led the discussion in the late 50's creation of Food Supply Centers (CEASA in Portuguese) in Brazil. The main objective of this study is to understand the role of CEASA-GO in the national market and identify the management improvements to be done in this institution. A descriptive research in operating manuals of the WM of Brazil; articles the time of the National System of Wholesale Markets (SINAC), the Ministry of Agriculture, Livestock and Supply in conjunction with the National Supply Company (Conab). Methodologically ranked research in descriptive exploratory, bibliographical, documentary and field having as object of study the Food Supply Center of Goiás and the data collection instrument was a questionnaire applied to private and public agents of this plant. The results show that the CEASA-GO had grown prodigiously since its beginning. This growth increased substantially the number of companies, workers and users inside the institution, bringing more demands. Besides that, the demands for more sustainable management models require changes that prioritize the environment and the society as a whole.
\end{abstract}

Keywords: Ceasa. Goiás. Management. Horticulture.

\footnotetext{
${ }_{1}^{1}$ Mestre em Desenvolvimento e Planejamento Territorial. karlakellem@globo.com

2 Doutor em Economia. Consultor da Food and Agriculture Organization-FAO/ONU e do Programa de Desenvolvimento das Nações Unidas PNUD/ONU. altivo.cunha@gmail.com

${ }^{3}$ Doutor em Fitotecnia. Professor da Pontifícia Universidade Católica de Goiás (PUC-GO) e do Instituto Federal de Educação Ciência e Tecnologia de Goiás. profpasqualetto@gmail.com

4 Mestrando em Desenvolvimento e Planejamento Territorial no Programa de Pós-Graduação da PUC-GO. taric_calil@hotmail.com

5 Doutor em Economia. Professor do Programa de Pós-Graduação em Desenvolvimento e Planejamento Territorial da PUC-GO.sergioucg@gmail.com
} 


\section{Introdução}

As centrais de abastecimento surgiram de uma iniciativa do governo em decorrência da precariedade em que eram comercializados os hortigranjeiros. Não existia nenhum controle nem normas instituídas para a operacionalização e comercialização desses produtos, além da falta de espaço e de estrutura física que atendessem a qualquer critério de qualidade.

O contexto histórico das centrais de abastecimento deve ser compreendido, avaliado, explorado e absorvido pelos seus dirigentes, pelo coletivo que faz parte das empresas e por suas associações, para que possam tomar atitudes conscientes quanto a seu papel diante dessas centrais e até mesmo diante do poder público que as dirige.

Em 1972, o Governo Federal decidiu criar o Sistema Nacional de Centrais de Abastecimento - SINAC -, ficando a Companhia Brasileira de Alimentos - COBAL - responsável pela gestão das ações voltadas para a organização e expansão do setor de hortigranjeiros, sendo considerada uma das iniciativas mais bem sucedidas no que se refere à obtenção de uma política voltada para este setor (ZEITUNE, 2011, p. 9).

As centrais de abastecimento (ceasas) são mercados atacadistas estruturados em pavilhões, divididos por segmentos, que reúnem um público diversificado. Sua atividade principal é o abastecimento do mercado de hortigranjeiros; sua atividade secundária contempla o comércio de embalagens, miudezas, eletrônicos, vestuário, entre outros, além de atividades de serviços complementares de bens e serviços, como restaurantes, lanchonetes, serviços automotivos, agências bancárias e outros.

Em meados da década de 1980, o Governo Federal, que detinha o controle das ações, começou a discutir a privatização das ceasas do Brasil, sendo o SINAC contrário a essa medida, já que a atividade de comercialização sempre fora privada. O que era gerido pelo Governo era apenas o complexo (MOURÃO; MAGALHÃES, 2011, p. 21).

Como o Governo Federal não conseguiu privatizá-las e não tinha o interesse em continuar a geri-las no modelo sistêmico implantado pelo SINAC, realizou-se, assim, a doação de todas as ações para seus respectivos estados e municípios. A CEAGESP e a CEASA-Minas foram casos específicos, pois eram estaduais, e foram federalizadas, pertencendo ainda à União. Com isso, rompeu-se a concepção sistêmica da intervenção governamental no setor, e cada estado fez da sua CEASA o que bem entendeu (ZEINUTE, 2011, p. 10).

Essas questões conduzem a uma reflexão mais profunda sobre o modelo de gestão, a evolução histórica das centrais de abastecimento, em especial a CEASA-GO, bem como seus aspectos positivos e negativos nos contextos social, político e econômico para um novo reordenamento.

O objeto desta pesquisa é a Central de Abastecimento do Estado de Goiás - CEASA-GO , que foi analisada em seu próprio ambiente físico, com base em documentos históricos, aplicação de questionário e entrevistas.

O objetivo central é compreender o planejamento e o modelo de uma gestão estatal operada por agentes privados no contexto da Central de Abastecimento de Goiás - CEASA-GO e apresentar perspectivas de melhorias. 
A pesquisa se torna relevante uma vez que a Central de Abastecimento de Goiás, desde seu surgimento, não passou por uma reestruturação que atendesse fisicamente à atual demanda do mercado e ao interesse de seus agentes privados.

\title{
2 Metodologia
}

Adotou-se a abordagem quali-quantitativa. A escolha ocorreu pelo fato desta lidar com as interpretações das realidades sociais, já que

\begin{abstract}
[...] é incorreto assumir que a pesquisa qualitativa possui o monopólio da interpretação, com o pressuposto paralelo de que a pesquisa quantitativa chega às suas conclusões quase que automaticamente. [...] O que a discussão sobre a pesquisa qualitativa tem conseguido foi desmistificar a sofisticação estatística como o único caminho para se conseguir resultados significativos. O prestígio ligado aos dados numéricos possui tal poder de persuasão que, em alguns contextos, a má qualidade dos dados é mascarada e compensada por uma sofisticação numérica (BAUER; GASKELL, 2002, p. 24).
\end{abstract}

A pesquisa se qualifica em dois aspectos: quanto aos fins e quanto aos meios. Quanto aos fins, a pesquisa será exploratória e descritiva, realizada na CEASA-GO. Exploratória, porque não se verificou a existência de estudos que abordem o planejamento e o modelo de gestão da Central de Abastecimento de Goiás para sugestão de melhorias. Descritiva, porque visa descrever a visão das pessoas que estão inseridas na CEASA-GO desde a sua fundação, retratando as mudanças no decorrer de mais de 30 anos de sua fundação.

Quanto aos meios, trata-se de um estudo de caso com pesquisa bibliográfica, documental e de campo, com observações e questionários sistematizados. A pesquisa foi um estudo de caso, por se tratar de empresas privadas, geridas por órgão público, por meio do qual se busca entender com detalhamento esse modelo de gestão e qual a sua interferência no planejamento e desenvolvimento da CEASA-GO. Bibliográfica, porque, para a fundamentação teórica, será realizada uma investigação em material acessível, como livros e artigos já publicados sobre os diversos temas relativos às centrais de abastecimento. Trata-se, também, de investigação documental, tendo por base os anuários publicados pela CEASA-GO, porque se valerá de documentos e fotos internas, os quais se referem a este objeto de estudo.

Foi realizada também uma pesquisa de campo com os diretores administrativos, aqui denominados agentes públicos, e com os concessionários, permissionários e autorizados (produtores), denominados agentes privados da CEASA-GO, visando colher suas opiniões a respeito da gestão da instituição e, com esses resultados, apresentar propostas de melhorias a serem implementadas.

\subsection{Delineamento do estudo}

O estudo do ambiente externo e das políticas públicas regulatórias das centrais de abastecimento revela sua importância, uma vez que as ameaças e oportunidades geradas pelo ambiente externo são fundamentais para possíveis mudanças, tanto no seu aspecto políticoadministrativo quanto em sua estrutura física. 


\section{Figura 1 - Fatores de Influência do Ambiente Externo na Central de Abastecimento de Goiás - CEASA-GO}

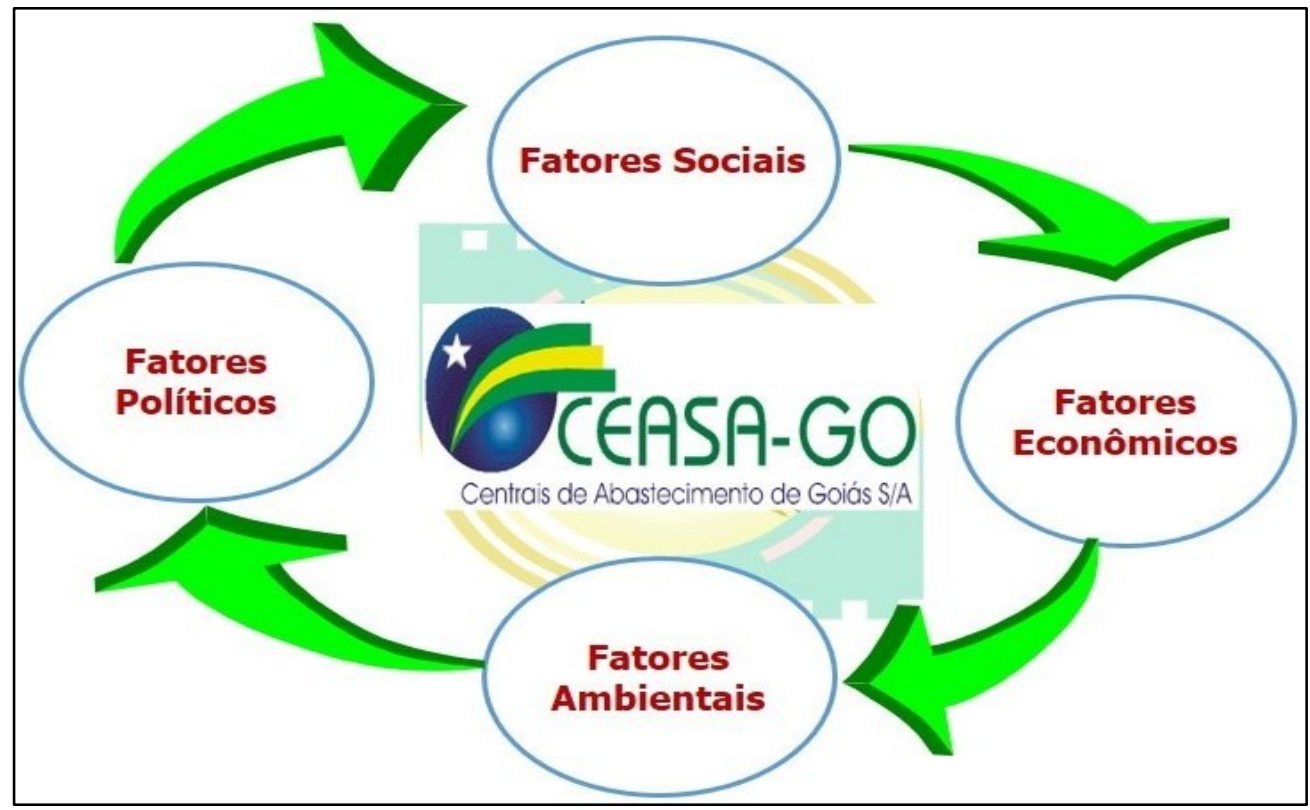

Fonte: Elaborado pelos autores (2015).

Para garantir essas mudanças no ambiente, faz-se necessário criar uma boa estratégia. "No setor público, a estratégia é definir os objetivos da organização e buscar a sintonia com as demandas da população" (MATIAS-PEREIRA, 2012, p. 116).

O planejamento pode ser visto como um conjunto de ações interligadas e complementares, realizadas nas diferentes instâncias da organização governamental, na intenção de atingir determinado objetivo (MATIAS-PEREIRA, 2012, p. 125). Sendo assim, a análise interna apresenta sua importância por compreender as práticas, o funcionamento e a rotina de atividades da organização de acordo com os processos a serem realizados.

\subsection{Universo e amostra do estudo}

Para a realização desta pesquisa, historiou-se o planejamento e o surgimento das centrais de abastecimento do Brasil, focalizando-se somente a CEASA-GO, sendo consideradas a gestão pública, as empresas privadas, a presidência da central, suas diretorias, os setores de operações, os concessionários, os permissionários, autorizados (produtores), funcionários e associações de classes pertencentes à CEASA-GO.

A amostra foi definida pelo critério de acessibilidade, pois seleciona os elementos pela sua facilidade de acesso e por tipicidade, constituindo-se de elementos que o pesquisador considere representativos da população-alvo (VERGARA, 2007, p. 51). Pelo critério de acessibilidade, foram definidos um diretor técnico-administrativo, gerentes e o presidente da associação UNIAP, totalizando 6 agentes públicos. Pelo critério de tipicidade, foram definidos os Concessionários, Permissionários e Autorizados (produtores). Reportou-se, principalmente, 
ao critério de tipicidade, em razão da dinâmica do mercado e da disponibilidade de participação nesta pesquisa (Tabela 1).

Quadro 1 - Amostra Pesquisada dos Agentes Privados e Públicos da Central de Abastecimento de Goiás - CEASA-GO

\begin{tabular}{|l|r|r|r|}
\hline \multicolumn{1}{|c|}{ População } & \multicolumn{1}{c|}{ Total Geral (n-) } & Amostra Pesquisada (no) & \% \\
\hline Concessionários & 151 & 31 & 20,52 \\
\hline Permissionários & 175 & 35 & 20,00 \\
\hline Autorizados & 308 & 31 & 10,06 \\
\hline Agentes públicos & 10 & 06 & 60,00 \\
\hline \multicolumn{1}{r|}{ Total } & $\mathbf{6 4 4}$ & $\mathbf{1 0 3}$ & $\mathbf{1 6 , 0 4}$ \\
\hline
\end{tabular}

Fonte: Elaborado pelos autores (2015).

Reportou-se, principalmente, ao critério de tipicidade, em razão da dinâmica do mercado e da disponibilidade para a participação neste estudo. Comunicou-se à diretoria a realização do estudo e expuseram-se os objetivos, a relevância da pesquisa, os procedimentos realizados e sua importância para um resultado fidedigno. Das etapas:

a) levantamento do referencial teórico, consulta ao histórico de criação das Ceasas do Brasil, em específico da CEASA-GO, e às normas, aos procedimentos e à legislação que as regem;

b) realização de visitas à CEASA-GO, para reconhecimento da estrutura física, institucional e funcional;

c) levantamento interno de todos os setores de funcionamento das CEASA-GO;

d) confecção e aplicação do instrumento de coleta de dados;

f) tratamento dos dados e apresentação do resultado.

\subsection{Os instrumentos e a coleta de dados}

O levantamento de dados consiste em tornar o entendimento de seu conteúdo mais simples. Neste estudo, optou-se pela revisão da literatura, a observação pessoal e o questionário, todos interligados, já que "[...] uma falha na revisão da literatura poderá trazer sérias dificuldades à concretização do questionário" (CURY, 2012, p. 289).

A revisão da literatura procura identificar, coletar e analisar os dados conforme a teoria; já a observação pessoal é um método de comparação que envolve a revisão da literatura, a aplicação de questionários e entrevistas, buscando a realidade dos fatos. Os questionários bem elaborados, especialmente neste estudo, são importantes, uma vez que a população total é composta por uma quantidade expressiva, impossível de ser contemplada nas entrevistas (CURY, 2012). 
Considerando o objeto de estudo, sua problemática e seus objetivos, optou-se pela aplicação de um questionário dividido em seis descritores ou blocos (Quadro 2). Estes abordaram o perfil (socioeconômico e por competências), a gestão da CEASA-GO (papel das associações de classe, programas e projetos da CEASA-GO, PROHORT e o novo Regulamento), a autonomia e responsabilidade (liberdade de administração, poder de tomada de decisão, normas e obrigações), a imagem e comunicação, fatores motivacionais/desmotivadores e o planejamento e espaço físico, com um total de cinquenta (50) questões, interligadas aos objetivos.

Os instrumentos de coleta de dados foram aplicados aos concessionários, aos permissionários e aos autorizados (produtores), sendo estes os agentes privados da CEASA-GO. Também à diretoria e aos setores de operações (esses setores são responsáveis pelos departamentos designados de divisões, sendo elas Divisão Técnica, Divisão de Operações de Mercado, Divisão de Atendimento ao Produtor, Divisão de RH, Divisão de TI, Divisão de Engenharia e Infraestrutura, Divisão Administrativa e Divisão Financeira) e aos agentes públicos.

O mesmo instrumento foi aplicado para os agentes privados e agentes públicos, com algumas questões diferenciadas, as quais não eram pertinentes ao setor público.

\section{Quadro 2 - Apresentação do Questionário Aplicado aos Agentes Privados e Agentes Públicos da Central de Abastecimento de Goiás - CEASA-GO - Interligado aos Objetivos}

\section{Problema de pesquisa:}

Com mais de 30 anos de operacionalização, a CEASA-GO está no limite de sua capacidade física e de serviços para atender às novas e complexas exigências dos mercados. Até quando vai isso? Como trabalhar o planejamento e o desenvolvimento da Ceasa-GO para suprir esse espaço obsoleto? $O$ que tem sido feito até agora? Qual o papel da gestão pública e das associações de classe na resolução deste entrave?

\section{Objetivo geral:}

Compreender o planejamento e o modelo de uma gestão estatal operada por agentes privados no contexto da Central de Abastecimento de Goiás - CEASA-GO - e a possibilidade de sugerir melhorias.

\begin{tabular}{l|l}
\hline Objetivos específicos & Perguntas do questionário \\
\hline $\begin{array}{l}\text { 1) Identificar o perfil dos agentes privados } \\
\text { e dos gestores públicos da CEASA-GO. }\end{array}$ & $\begin{array}{l}\text { BLOCO 1 - PERFIL } \\
\text { Perfil socioeconômico } \\
\text { Perfil de competências }\end{array}$ \\
\hline 2) Identificar os resultados de uma gestão & BLOCO 2 - GESTÃO DA CEASA-GO \\
estatal operada por agentes privados. & $\begin{array}{l}\text { Papel das associações de classes } \\
\text { Programas e projetos da CEASA-GO }\end{array}$ \\
3) Analisar o papel das associações dentro & PROHORT - Programa Brasileiro de Modernização do \\
da Central de Abastecimento de Goiás. & Mercado Hortigranjeiro. \\
& Novo Regulamento de Mercado da CEASA-GO. \\
\hline 4) Verificar a autonomia e a & BLOCO 3 - AUTONOMIA E RESPONSABILIDADE \\
responsabilidade dos agentes privados & Liberdade de administração \\
perante a CEASA-GO. & Poder de tomada de decisão \\
Normas e obrigações
\end{tabular}




\begin{tabular}{l|l}
\hline Objetivos específicos & Perguntas do questionário \\
\hline $\begin{array}{l}\text { 5) Identificar a imagem da CEASA-GO - aos } \\
\text { olhos de seus agentes privados e de seus } \\
\text { gestores, e como ambos se comunicam. }\end{array}$ & $\begin{array}{l}\text { BLOCO 4 - IMAGEM E COMUNICAÇÃO DA CEASA-GO } \\
\text { Imagem da CEASA-GO } \\
\text { Comunicação entre seus agentes } \\
\text { Orientações }\end{array}$ \\
\hline $\begin{array}{l}\text { 6) Compreender os fatores motivacionais } \\
\text { e desmotivadores que levam os agentes } \\
\text { privados a continuarem com seus negócios } \\
\text { na CEASA-GO. }\end{array}$ & $\begin{array}{l}\text { BLOCO 5 - FATORES MOTIVACIONAIS/ } \\
\text { DESMOTIVADORES }\end{array}$ \\
\hline $\begin{array}{l}\text { Fatores que geram satisfação para permanecer na } \\
\text { CEASA-GO }\end{array}$ \\
$\begin{array}{l}\text { Fatores que geram insatisfação na convivência e } \\
\text { permanência na CEASA-GO }\end{array}$ \\
$\begin{array}{l}\text { BLOCO 6 - PLANEJAMENTO E ESPAÇO FíSICO } \\
\text { melhoria à CEASA-GO. }\end{array}$ \\
$\begin{array}{l}\text { Segmentação do mercado } \\
\text { Planejamento do espaço físico } \\
\text { Propostas de melhoria para a CEASA-GO }\end{array}$ \\
\hline
\end{tabular}

Fonte: Elaborado pelos autores (2015).

Os acervos de documentos históricos específicos da CEASA-GO, como fotografias e vídeos, também foram elementos desta coleta de dados. $O$ acesso a esse material foi possível no site da CEASA-GO, em grande parte, além da parte concedida pelo Departamento de Gerência Técnica de Mercado.

\section{A Central de Abastecimento de Goiás - CEASA-GO em números}

A CEASA-GO tornou-se o quarto maior complexo de abastecimento do país. Atualmente, são 175 (cento e setenta e cinco) empresas instaladas. A média histórica (últimos seis anos) da estimativa de comercialização é superior a um bilhão de reais (CEASA-GO, 2015).

Em 2010, registrou-se a quantidade de 783.324,52 toneladas de hortigranjeiros, e, no aspecto financeiro, o montante de $\mathrm{R} \$ 1,075$ bilhão. $\mathrm{O}$ ano de 2011, movimentou 843.077,63 toneladas, sendo que a movimentação financeira foi de 1,22 bilhão de reais. 0 ano de 2012 ofertou a quantidade de $864.567,59$ toneladas de hortigranjeiros e movimentou 1,55 bilhão de reais. Em 2013, a quantidade ofertada na Ceasa-GO foi de 873.310,15 toneladas, proporcionando um movimento financeiro de 1,85 bilhão de reais. O ano de 2014 foi de 913.814,99 toneladas, girando um montante financeiro de 1,7 bilhão de reais. Em 2015, a CEASA-GO teve $931.676,71$ toneladas negociadas por 2,11 bilhões de reais (DIVITEC/CEASA-GO, 2015).

A série histórica da CEASA-GO revela o crescimento na oferta de produtos e justifica sua classificação no 4ㅇ lugar do ranking nacional em relação aos volumes quantitativos e aos valores financeiros comercializados, conforme o Quadro 3. 
Quadro 3 - Classificação das principais Ceasas brasileiras (PROHORT) em 2016

\begin{tabular}{|l|l|l|l|l|l|}
\hline \multirow{2}{*}{ ORDEM } & \multicolumn{2}{|c|}{ CEASAS } & \multicolumn{2}{c|}{ HORTIGRANJEIRO (KG) } & \multicolumn{2}{c|}{ HORTIGRANJEIRO (R\$) } \\
\cline { 3 - 6 } & & \multicolumn{1}{|c|}{$\mathbf{2 0 1 6}$} & \multicolumn{2}{c|}{ ORDEM } & \multicolumn{2}{c|}{$\mathbf{2 0 1 6}$} & ORDEM \\
\hline 1 & $\begin{array}{l}\text { CEAGESP - } \\
\text { São Paulo }\end{array}$ & 3.142 .956 .335 & $1^{\circ}$ & $10.049 .635 .315,81$ & $1^{\circ}$ \\
\hline 2 & $\begin{array}{l}\text { CEASA-MG - } \\
\text { Grande BH }\end{array}$ & 1.467 .785 .174 & $2^{\circ}$ & $3.065 .853 .462,97$ & $3^{\circ}$ \\
\hline 3 & $\begin{array}{l}\text { CEASA-RJ - } \\
\text { Rio de Janeiro }\end{array}$ & 1.292 .020 .303 & $3^{\circ}$ & $3.148 .710 .116,85$ & $2^{\circ}$ \\
\hline 4 & $\begin{array}{l}\text { CEASA-GO - } \\
\text { Goiânia }\end{array}$ & $\mathbf{8 8 6 . 4 8 2 . 5 9 3}$ & $\mathbf{4}^{\circ}$ & $\mathbf{2 . 5 2 5 . 8 2 9 . 4 2 7 , 7 7}$ & $\mathbf{4}^{\circ}$ \\
\hline 5 & $\begin{array}{l}\text { CEASA-PR - } \\
\text { Curitiba }\end{array}$ & 679.029 .040 & $5^{\circ}$ & $1.536 .740 .533,02$ & $7^{\circ}$ \\
\hline 6 & CEASA-PE - Recife & 634.418 .997 & $6^{\circ}$ & $1.603 .681 .410,17$ & $6^{\circ}$ \\
\hline 7 & $\begin{array}{l}\text { CEASA-SP - } \\
\text { Campinas }\end{array}$ & 610.982 .593 & $7^{\circ}$ & $1.670 .526 .972,42$ & $5^{\circ}$ \\
\hline 8 & $\begin{array}{l}\text { CEASA-RS - Porto } \\
\text { Alegre }\end{array}$ & 583.042 .135 & $8^{\circ}$ & $1.457 .574 .191,31$ & $6^{\circ}$ \\
\hline 9 & $\begin{array}{l}\text { CEASA-CE - } \\
\text { Fortaleza }\end{array}$ & 491.752 .971 & $9^{\circ}$ & $1.250 .265 .948,14$ & $9^{\circ}$ \\
\hline 10 & CEASA-ES - Vitória & 387.438 .410 & $10^{\circ}$ & $877.589 .949,88$ & $10^{\circ}$ \\
\hline TOTAL & & $\mathbf{1 6 . 1 6 6 . 4 6 6 . 8 8 6}$ & & $\mathbf{2 9 . 5 2 8 . 3 5 8 . 7 1 4 , 6 9}$ & \\
\hline
\end{tabular}

Fonte: Elaborado pelos autores (2017), adaptado de PROHORT/CONAB (2017).

Estes dados são de responsabilidade de cada Central de Abastecimento, sendo organizados e divulgados pela Companhia Nacional de Abastecimento - CONAB - através do Programa Brasileiro de Modernização do Mercado Hortigranjeiro (PROHORT). O crescimento da Central de Abastecimento de Goiás pode ser observado no Gráfico 1, que apresenta a evolução na oferta anual de hortigranjeiros dentro da CEASA-GO, bem como a participação do estado de Goiás na oferta total. 


\section{Gráfico 1 - Evolução da Comercialização da Central de Abastecimento de Goiás - CEASA-GO}



Fonte: Elaborado pelos autores, adaptado de DIVTEC/CEASA-GO, 2015.

A análise conjuntural da comercialização da CEASA-GO faz um levantamento da quantidade total em toneladas e a participação do estado de Goiás na comercialização de seus produtos. Em 2015, ano da última análise conjuntural disponibilizada pela CEASA-GO, essa Central apresentou uma média de comercialização mensal de 77,6 mil toneladas e de 2,9 mil ton./dia, considerando somente os dias comercializados (DIVITEC/CEASA-GO, 2015).

Os produtos oriundos do estado de Goiás totalizaram 451.796,68 toneladas, média superior em $6 \%$ em relação ao volume do ano anterior, quando foram comercializadas $426.316,71$ toneladas. O percentual da participação do estado no volume total foi de $48,49 \%$. Como pode ser observado, apesar da reação na oferta, o índice continua abaixo dos $50 \%$, o que é considerado preocupante. Levando em conta que, no ano de 2002, o estado participou com $60,42 \%$, correspondendo a 462 mil toneladas, observou-se uma redução de $2,2 \%$ em relação ao ano de 2015 (DIVITEC/CEASA-GO, 2015).

Todas as dezoito (18) microrregiões do estado tiveram participação efetiva na oferta da Ceasa-GO. A principal microrregião foi a de Goiânia (que conta com dezesseis (16) municípios), ofertando $156.102,18$ toneladas, o que representa $34,55 \%$ da oferta do estado e $16,75 \%$ da oferta geral. A movimentação financeira dessa microrregião foi de 352,9 milhões de reais. A microrregião de Anápolis (com dezenove (19) municípios), por sua vez, foi a segunda colocada, com $134.241,52$ toneladas, $29,71 \%$ da oferta do estado e $14,41 \%$ da oferta total. A movimentação financeira foi de 240,7 milhões de reais. A terceira colocada, a microrregião do entorno de Brasília, forneceu 88.104,73 toneladas, 19,50\% da oferta do estado, 9,46\% da oferta geral, com um giro financeiro de 195 milhões de reais. Essas três microrregiões representaram 83,77\% da oferta do estado e 40\% da oferta geral na Ceasa-GO em 2015.

A análise da divisão técnica da CEASA-GO deduz que houve um aumento considerável do consumo, possivelmente motivado pelo aumento populacional e também pela melhora do poder aquisitivo da população. Em contrapartida, percebe-se que o estado não reagiu 
produtivamente na mesma proporção do consumo, culminando com o aumento da importação de produtos de outras regiões do país (DIVITEC/CEASA-GO, 2015).

Outro fator significativo, que pode ter influência na produção de hortigranjeiros em Goiás, é o aumento da produção de soja, milho e cana-de-açúcar em relação a outros cultivos da cadeia alimentar.

Silva (2015, p. 57) reporta seus estudos à área de ocupação da cana-de-açúcar, no estado de Goiás, e ao efeito de substituição em relação a outras culturas de abastecimento alimentar, nos anos de 2003 a 2012, no modelo de Shift-Share, que é aplicado para verificar essas alterações na produção em decorrência do efeito substituição.

Faz-se importante apresentar como está ocorrendo essa ocupação (variação nas áreas plantadas para verificar a sua substituição) para compreender se este foi realmente um fator significativo na queda da participação de Goiás na comercialização de seus produtos na CEASAGO, já que, entre 2000 e 2003, a participação do estado variou de $64,18 \%$ a 60,40\%. O período entre 2003 a 2012 é exatamente o período em que a soja, o milho e a cana-de-açúcar foram as culturas que mais ocuparam o espaço goiano.

A soja ocupou uma área somada ano a ano de 24.264.746 hectares. A cultura de milho ocupa a segunda posição em área ocupada no estado, com uma área soma ano a ano de 8.404.024 hectares. Durante o período analisado, a cultura de cana-de-açúcar aparece na terceira posição, com uma área ocupada de 3.978.217 hectares (SILVA, 2015, p. 57).

Silva (2015, p. 60) explica que o efeito positivo de substituição mostra que a participação das culturas de soja, milho e cana-de-açúcar aumentou, pois outras culturas foram substituídas por estas. Já no caso do efeito negativo de substituição, há um indício de que a participação da cultura reduziu no sistema agrícola.

A cana-de-açúcar, o milho e a soja apresentaram um valor positivo e acentuado para o indicador do efeito substituição do modelo Shift-Share proposto por Silva (2015). A cana-deaçúcar teve um efeito substituição de 544.928,46 hectares, enquanto o efeito substituição do milho foi de $404.866,42$ hectares. No mesmo período analisado, a soja teve um efeito substituição de $188.433,20$ hectares.

Esses dados mostram que o cultivo da cana-de-açúcar, do milho e da soja vem substituindo as demais culturas, que apresentaram resultados negativos do mesmo indicador, "[...] assim, fica caracterizado que toda cultura negativa pode ser substituída pelas culturas com valores positivos, neste mesmo efeito" (SILVA, 2015, p. 59).

Considera-se, assim, que o efeito substituição das culturas da soja, milho e cana-deaçúcar não interferiu diretamente na produção dos hortigranjeiros de Goiás, já que essas culturas possuem quantidades superiores em relação às outras culturas que sofreram redução de produção no sistema agrícola. Dessa forma, pode-se dizer que o problema está mais voltado a questões políticas, econômicas e até mesmo a problemas ambientais, como a crise hídrica.

O estado de Goiás é forte na área da agricultura, mas o pequeno agricultor tem encontrado grandes dificuldades, algumas já identificadas, tais como a escassez e o encarecimento da mão de obra, a alta dos insumos e a falta de recursos financeiros. É do conhecimento da maioria que os agentes responsáveis pela horticultura da produção agrícola 
são pequenos e médios produtores, estando, portanto, vulneráveis a qualquer contratempo, já que seus produtos são altamente perecíveis, ao contrário dos grãos, como a soja e o milho, que podem ser armazenados (DIVITEC/CEASA-GO, 2012, p. 5).

A Central de Abastecimento de Goiás comercializa mais de 240 produtos, sendo estes divididos em grupos e subgrupos de produtos. O grupo das hortaliças é subdividido em três segmentos: folhas, flor, haste; frutos e raiz, tubérculos, bulbo. O grupo das frutas está dividido em nacionais e importadas. Os grupos restantes referem-se a aves e ovos; produtos diversos e cereais. No Quadro 4 apresenta-se a quantidade (tonelada) e o valor da comercialização por grupo de produtos da CEASA-GO entre 2011 e 2015. 
Quadro 4 - Quantidade (Tonelada) e valor da comercialização por grupo de produtos da CEASA-GO dos anos 2011 a 2015

\begin{tabular}{|c|c|c|c|c|c|c|c|c|}
\hline & \multicolumn{2}{|c|}{ ANO 2011} & \multicolumn{2}{|c|}{ ANO 2012} & \multicolumn{2}{|c|}{ ANO 2013} & \multicolumn{2}{|c|}{ ANO 2014} \\
\hline & $\begin{array}{l}\text { QUANTIDADE } \\
\text { (TONELADA) }\end{array}$ & $\begin{array}{c}\text { VALOR EM } \\
1.000 \mathrm{R} \$\end{array}$ & $\begin{array}{l}\text { QUANTIDADE } \\
\text { (TONELADA) }\end{array}$ & $\begin{array}{c}\text { VALOR } \\
\text { EM } 1.000 \text { R\$ }\end{array}$ & $\begin{array}{l}\text { QUANTIDADE } \\
\text { (TONELADA) }\end{array}$ & $\begin{array}{c}\text { VALOR } \\
\text { EM } 1.000 \text { R\$ }\end{array}$ & $\begin{array}{l}\text { QUANTIDADE } \\
\text { (TONELADA) }\end{array}$ & $\begin{array}{l}\text { VALOR EM } \\
1.000 \mathrm{R} \$\end{array}$ \\
\hline HORTALIÇAS & $423.151,20$ & $454.080,31$ & $418.128,29$ & 607.618.280,15 & $455.375,47$ & $828.255 .903,89$ & $486.030,34$ & $794.190 .268,50$ \\
\hline FOLHAS, FLOR, HASTE & $42.232,88$ & $29.908,21$ & $48.134,91$ & $39.796 .510,75$ & $48.670,26$ & $51.911 .351,00$ & $51.955,72$ & $50.092 .564,27$ \\
\hline FRUTO & $182.893,47$ & $238.238,49$ & $173.826,08$ & 298.917.830,62 & $195.963,97$ & $390.130 .494,20$ & $213.011,95$ & $399.172 .605,69$ \\
\hline RAIZ, TUBÉRCULOS, BULBO & $198.024,85$ & $185.933,61$ & $196.167,30$ & $268.903 .938,78$ & $210.741,24$ & $386.214 .058,69$ & $221.062,67$ & $344.925 .098,54$ \\
\hline FRUTAS & $375.955,00$ & $519.699,10$ & $416.805,48$ & $870.807 .354,58$ & $383.495,77$ & $911.343 .467,25$ & $397.850,98$ & $800.259 .584,98$ \\
\hline NACIONAIS & $370.816,27$ & $495.246,13$ & $409.153,13$ & $828.271 .090,18$ & $371.826,12$ & $841.625 .214,92$ & $390.001,01$ & $751.840 .684,33$ \\
\hline IMPORTADAS & $5.138,73$ & $24.452,97$ & $7.652,35$ & $42.536 .264,40$ & $11.669,65$ & $69.718 .252,33$ & $7.849,97$ & $48.418 .900,65$ \\
\hline AVES E OVOS & $30.847,69$ & $80.083,98$ & $19.099,43$ & $51.879 .436,54$ & $18.303,82$ & $60.151 .162,93$ & $17.224,65$ & $63.068 .858,12$ \\
\hline PRODUTOS DIVERSOS & $9.878,94$ & $27.761,84$ & $7.018,90$ & $20.218 .020,14$ & $11.649,49$ & $45.756 .209,90$ & $9.667,86$ & $35.911 .135,46$ \\
\hline CEREAIS & $3.244,80$ & $6.792,93$ & $3.515,49$ & $9.388 .004,13$ & $4.485,60$ & $13.232 .079,74$ & $3.041,16$ & $7.594 .864,42$ \\
\hline TOTAL & $843.077,63$ & $1.088 .418,16$ & $864.567,59$ & 1.559.911.095,54 & $873.310,15$ & $1.858 .738 .823,71$ & $913.814,99$ & $1.701 .024 .711,48$ \\
\hline
\end{tabular}

Fonte: Elaborado pelos autores, adaptado de DIVTEC/CEASA, 2015. 
O grupo das hortaliças vem se destacando nos últimos anos, apresentando um crescimento significativo em quantidade (toneladas). Em 2011, a CEASA-GO comercializou a quantidade de 423.151,20t, passando para 497.632,98t em 2015. Já o grupo das frutas teve uma oscilação entre os anos de 2011, 2012 e 2014; a quantidade de comercialização, que estava crescendo, foi de 375.955,00t, em 2011, e teve um aumento significativo em 2012, passando a comercializar $416.805,48$ t. Em 2013, houve um declínio considerável no processo, voltando a crescer e atingir 397.850,98t, comercializadas em 2014. O ano de 2015 permaneceu estável, com 397.218,93t, ficando ainda abaixo da quantidade comercializada em 2012 (DIVITEC/CEASA-GO, 2015).

O grupo das aves e ovos passou por situação ainda pior que o grupo das frutas. Em 2011, a comercialização chegou a 30.847,69t, mas caiu vertiginosamente, em 2012, quando comercializadas 19.099,43t; em 2013, 18.303,82t, e, em 2014, 17.224,65t. Os produtos diversos e os cereais flutuaram pouco nesse período de cinco anos, sendo comercializados, em 2015, $11.159,30$ t de produtos diversos e 4.140,01t de cereais. Mesmo com a queda na comercialização de alguns grupos, este fator não interferiu no total da comercialização, já que, em 2010, foram comercializadas na CEASA-GO 783.324,52t; em 2011, 843.077,63; em 2012, 864.567,59t; em 2013, 873.310,15t; em 2014, 913.814,99t; em 2015, 931.676,71 toneladas (DIVITEC/CEASA-GO, 2015).

No ano de 2015, das 27 unidades federativas (incluindo-se o DF), 81\% tiveram participação na oferta de produtos na Ceasa-GO. Os cinco principais estados com o maior índice de participação, em 2015, são os estados de Goiás, que lidera em primeiro lugar, ofertando $451.796,68 t$, o equivalente a 48,49\% da oferta geral no mesmo ano; o estado de São Paulo, que se encontra em segundo lugar na participação de oferta, com 125.688,36t, 13,49\% da participação; Minas Gerais, que aparece em terceiro lugar, com 100.516,80t, 10,78\% da oferta. O estado mineiro é seguido pelo de Santa Cataria, com 77.914,59t, 8,36\% da oferta, e pelo estado da Bahia, com 75.505,80t, 8,10\% da oferta (DIVITEC/CEASA-GO, 2015).

É interessante notar que, de toda a participação da região Centro-Oeste na oferta de produtos da CEASA-GO, o estado de Goiás é responsável por 99,40\%. Nas divisões regionais do Brasil, todas tiveram participação efetiva na oferta de produtos na CEASA-GO em 2015. Pela ordem de quantidade ofertada, estão Região Centro-Oeste, com 454.538,88t, perfazendo um percentual de $48,79 \%$ do total; em segundo lugar, a região Sudeste, ofertando $241.594,01 t$, equivalendo a $25,93 \%$ da oferta. Em terceiro lugar, aparece a região Sul, com a oferta de $125.329,35 t$ e $13,45 \%$ de participação. A região Nordeste encontra-se em quarto lugar, ofertando $91.026,70 t$, sendo 9,77\% do geral. E, em quinto e último lugar, a região Norte, que ofertou apenas $19.187,76 \mathrm{t}$, sendo $2,06 \%$ de participação na oferta (DIVITEC/CEASA-GO, 2015). Em comparação com os dados de 2014, é interessante notar a queda da região Nordeste na colocação geral, que acabou sendo substituída pela região Sul.

Em 2015, o volume dos produtos importados somou $28.818,38 \mathrm{t}, 3,09 \%$ da oferta geral no mercado. Desse montante, 35,29\% foram da importação de alho e cebola, num total de $10.168,58$ toneladas, provenientes da Argentina, Chile, México, Espanha, Holanda e da China. Os outros 64,71\% do montante importado refere-se às frutas finas, procedentes da Argentina, Chile, Itália, Espanha, USA, Portugal e Nova Zelândia (DIVITEC/CEASA-GO, 2015).

Em relação aos principais produtos comercializados, a batata e a maçã aparecem, respectivamente, em primeiro e segundo lugares em 2015, sendo que a batata totalizou $104.518,85$ toneladas, girando um montante de 192,5 milhões de reais, e com participação de 
39,34\% do estado de Goiás. A maçã, por sua vez, somou 88.516,97 toneladas ofertadas, correspondendo a 247,4 milhões de reais e apenas $0,41 \%$ de participação do estado. Os outros produtos mais ofertados foram o tomate, com 87.926,64 toneladas e 76,67\% de participação goiana, seguido da laranja, com $72.887,74$ toneladas e $20,52 \%$ de participação de Goiás, e do repolho, com 50.578,17 toneladas e 54,90\% de participação do estado (DIVITEC/CEASA-GO, 2015).

A Central de Abastecimento de Goiás, mesmo com um número positivo em sua comercialização e estando em 4으 lugar no ranking nacional de Centrais de Abastecimento, enfrenta problemas que vão além da fluidez do mercado. Faz-se necessária a adequação a um mundo repleto de mudanças, o que requer soluções imediatas, principalmente em seu espaço físico, que não comporta o fluxo diário de motos, carros, caminhões e pessoas.

\section{CEASA-GO e perspectivas de melhoria}

Em um mundo em constante transformação, carregado de incertezas, aumenta a necessidade de opções que visem solucionar os diversos problemas que vêm confrontando a realidade das empresas públicas e privadas. A era da informação e do conhecimento impõe ao mundo contemporâneo desenvolver-se de forma econômica e sustentável, em um ambiente onde a mudança de paradigmas e de valores seja constante, causando profundo impacto na sociedade em todos os seus setores - econômicos, sociais, ambientais, culturais e tecnológicos. Isso força os governos, as administrações públicas e privadas a repensarem a questão da governança e do modelo de gestão pública com relação à sociedade (MATIAS-PEREIRA, 2012).

Inserida nesse contexto, a Central de Abastecimento de Goiás deve preocupar-se em incorporar as novas tecnologias e inovações para uma gestão corporativa que, na prática, vá atender às demandas do setor de abastecimento. A comercialização das Centrais de Abastecimento possui uma característica particular, por ter como atividade principal o comércio de produtos hortigranjeiros. Isso faz com que o mercado se torne mais dinâmico e eficiente na consolidação e distribuição de seus produtos.

Responsável pelo suprimento alimentar do estado de Goiás, a Central de Abastecimento de Goiás (CEASA-GO) possui um compromisso não só com o estado, mas também com outras unidades federativas. Mesmo configurando um cenário positivo de mudanças, a CEASA-GO deve ser repensada em seu contexto atual e revistas suas políticas públicas.

Esta pesquisa identificou alguns pontos fracos no planejamento, gestão e desenvolvimento da CEASA-GO, e, a partir desses pontos, foram elaboradas propostas de melhorias, que foram divididas em quatro blocos: gestão, produtos, processos e planejamento (Quadro 5). Vale ressaltar que os aspectos apresentados foram apontados tanto pelos agentes privados como pelos agentes públicos da CEASA-GO.

Com relação às propostas de melhoria na gestão da CEASA-GO, faz-se necessário expor que algumas delas já foram contempladas em parte. No que se refere à redução de diretorias, esta foi contemplada no início do ano de 2015, como cumprimento das propostas do governo de Goiás em extinguir algumas diretorias. A proposta original seria a extinção de diretorias e de chefia de gabinete, permanecendo o presidente e um diretor técnico-administrativo, mas esta proposta não foi ao todo contemplada, permanecendo a chefia de gabinete. 
Quadro 5 - Quadro síntese das propostas de melhoria da CEASA-GO

\begin{tabular}{|c|c|c|}
\hline ÁREA & ASPECTOS & PROPOSTAS \\
\hline \multirow{16}{*}{$\begin{array}{l}G \\
E \\
S \\
T \\
\tilde{A} \\
O\end{array}$} & \multirow{7}{*}{$\begin{array}{c}\text { Reforma } \\
\text { Administrativa }\end{array}$} & Capacitação dos colaboradores \\
\hline & & Inclusão de atacadistas \\
\hline & & Redução de diretorias \\
\hline & & Redução do empreguismo \\
\hline & & Abertura de concurso público \\
\hline & & Redução do aluguel e taxas \\
\hline & & Planejamento estratégico eficaz \\
\hline & \multirow{4}{*}{ Fiscalização } & Regulação do mercado \\
\hline & & Cumprimento das normas e obrigações \\
\hline & & Controle de mercadoria \\
\hline & & Fiscalização dos produtores \\
\hline & \multirow{3}{*}{ Associações de classe } & Associação mais atuante em parceria com a diretoria \\
\hline & & Transparência de gestão \\
\hline & & Parcerias no setor empresarial \\
\hline & \multirow{2}{*}{ Imagem e comunicação } & Modernização do mercado \\
\hline & & Marketing digital \\
\hline \multirow{10}{*}{$\begin{array}{l}\mathrm{P} \\
\mathrm{R} \\
\mathrm{O} \\
\mathrm{D} \\
\mathrm{U} \\
\mathrm{T} \\
\mathrm{O} \\
\mathrm{S}\end{array}$} & \multirow{7}{*}{ Mercadorias } & Controle e qualidade \\
\hline & & Ampliação do Mix de produtos \\
\hline & & Redução do uso de agrotóxicos \\
\hline & & Comercialização de orgânicos \\
\hline & & Redução do descarte dos perecíveis em bom estado de consumo \\
\hline & & Ampliação das doações \\
\hline & & Fiscalização da comercialização de produtos ilegais \\
\hline & \multirow{3}{*}{ Embalagens } & Padronização de embalagens \\
\hline & & Higienização das embalagens \\
\hline & & Comercialização de produtos cartelados \\
\hline \multirow{11}{*}{$\begin{array}{l}P \\
R \\
O \\
C \\
E \\
S \\
S \\
O \\
S\end{array}$} & \multirow{4}{*}{ Banco de Caixas } & Controle das embalagens vazias antes de entrarem no mercado \\
\hline & & Proibição do empréstimo de caixas plásticas \\
\hline & & Higienização \\
\hline & & Padronização das embalagens \\
\hline & \multirow{4}{*}{ Portaria } & Controle de entrada e saída no mercado \\
\hline & & Portarias eletrônicas \\
\hline & & Cadastro dos usuários \\
\hline & & Criação de banco de dados \\
\hline & \multirow{3}{*}{ Energia } & Divisão da distribuição de energia por pavilhão \\
\hline & & Disponibilização de geradores de energia para os pavilhões \\
\hline & & Instalação de uma nova rede de energia subterrânea \\
\hline \multirow{12}{*}{$\begin{array}{c}P \\
L \\
A \\
N \\
E \\
J \\
A \\
M \\
E \\
N \\
T \\
O\end{array}$} & \multirow{6}{*}{ Ampliação de espaços } & Construção de novos galpões comerciais \\
\hline & & Construção do Mercado de Flores e de Peixes \\
\hline & & Construção do Mercado de Orgânicos \\
\hline & & Construção de um galpão voltado para agricultura familiar \\
\hline & & Construção de dormitórios \\
\hline & & Melhor distribuição dos banheiros \\
\hline & \multirow{4}{*}{ Trânsito } & Expansão da área de estacionamento e movimentação de cargas \\
\hline & & Expansão do estacionamento de carros de passeio \\
\hline & & Sinalização clara e objetiva \\
\hline & & Implantação de corredores exclusivos para carrinhos e empilhadeiras \\
\hline & \multirow{2}{*}{ Ambiente interno } & Instalação de bebedouros em todo mercado \\
\hline & & Instalação de lixeiras sustentáveis \\
\hline
\end{tabular}

Fonte: Elaborado pelos autores (2017). 
A Central de Abastecimento de Goiás conta com um quadro efetivo escasso, sendo os principais cargos ocupados praticamente desde o início de suas atividades, quando seus colaboradores foram efetivados por trabalharem no setor antes da Constituição de 1988, que definiu a realização de concursos para ocupação de cargos públicos. Desde então, a CEASA-GO não realizou nenhum concurso para a contratação de novos servidores, aderindo à contratação de estagiários para a execução dos serviços.

Outra proposta pertinente refere-se à inclusão de atacadistas de outros segmentos na Central de Abastecimento, contemplando em um só espaço as necessidades dos clientes. Uma fiscalização eficiente reduziria a entrada de atravessadores na CEASA-GO, os quais tentam comercializar seus produtos de forma ilegal, prejudicando diretamente os produtores. $O$ cumprimento das normas e obrigações destinadas a todos os usuários e frequentadores da CEASAGO reduziria boa parte dos problemas enfrentados dentro do espaço físico dessa central de abastecimento.

Nesta pesquisa na CEASA-GO, verificou-se a insatisfação dos agentes privados e públicos com as associações de classes. Nesse sentido, faz-se necessária, em suas atividades, dinamização, interação e participação ativa com a Diretoria da CEASA-GO, em busca de melhorias para o setor que elas defendem. Mesmo estando classificada entre as melhores centrais de abastecimento do Brasil, a CEASA-GO deveria trabalhar sua imagem e comunicação, divulgando todas as atividades, atualizando diariamente todas as informações do site e trabalhando efetivamente o marketing digital, no intuito de uma modernização do mercado.

Outro conjunto de propostas de melhorias refere-se aos produtos comercializados na CEASA-GO, sendo necessário um controle maior da qualidade desses produtos, a ampliação do Mix de produtos comercializados na CEASA-GO, além da consolidação de um programa efetivo dessa central de abastecimento para a redução do uso de agrotóxicos, com palestras, cursos e orientações periódicas aos produtores rurais.

O Brasil vive uma realidade de consumidores cada vez mais exigentes e preocupados com uma alimentação saudável. A busca pela qualidade de vida vem crescendo cada vez mais, e este fato interfere diretamente no setor alimentício, proporcionando a possibilidade de comercialização de produtos orgânicos dentro da CEASA-GO. Esta é uma cultura promissora, já que o meio ambiente clama por cuidados especiais.

Outra realidade da CEASA-GO é o descarte indiscriminado de mercadorias ainda em bom estado de consumo, que são despejadas diretamente nos contêineres e vão parar no aterro sanitário. Já que o Banco de Alimentos não comporta, em determinadas épocas, todos os produtos destinados a doações, sugere-se à CEASA-GO a criação de um projeto, no qual os fazendeiros criadores de animais da grande Goiânia pudessem se cadastrar e firmar uma parceria com os agentes privados da CEASA-GO. Estes fazendeiros recolheriam os alimentos descartados e ainda em bom estado - e os utilizariam na produção de ração e alimentação de seus animais.

Em relação às embalagens dos produtos, faz-se necessária uma modernização do mercado, com uma padronização dessas embalagens. Além disso, recomenda-se expandir a comercialização de produtos cartelados, posto que há uma demanda crescente nesse setor.

O terceiro bloco de sugestões refere-se aos processos. No que diz respeito ao Banco de Caixas, este possui papel fundamental na organização do mercado da CEASA-GO. Com a 
padronização e as exigências de higienização das caixas plásticas, o Banco de Caixas deveria ser mais atuante e eficaz na realização de seus serviços, controlando a entrada e saída dessas embalagens no mercado. Isso reduziria a demanda de empréstimos de caixas plásticas, amenizando os problemas enfrentados pelos agentes privados com relação ao alto investimento diário na aquisição dessas embalagens.

Outro processo importante refere-se às portarias da Central de Abastecimento, que não possuem um controle maior dos usuários da CEASA-GO. Isso compromete a segurança dos usuários do mercado. A criação de um banco de dados, com o cadastro de todas as pessoas que circulam nas dependências da CEASA-GO, seria uma ação pertinente, pois, além de garantir maior segurança aos usuários, a CEASA-GO teria informações mais precisas de seus fornecedores e clientes.

Em relação à energia da Central de Abastecimento, esta merece um cuidado especial, já que não comporta a distribuição para as redes elétricas. Em épocas de muito calor, os padrões esquentam muito, cortando o fornecimento de energia. Devido a estes problemas constantes, alguns pavilhões da CEASA-GO se uniram para a compra de geradores de energia, para sanar os problemas diários de fornecimento.

Por fim, o último conjunto de sugestões apresenta propostas de melhorias ligadas às áreas de planejamento e infraestrutura, sendo estes aspectos os mais citados pelos agentes privados e públicos e que necessitam de maiores investimentos. Das propostas aqui apresentadas, algumas já fazem parte dos projetos do governo do estado de Goiás, como a ampliação da Central de Abastecimento, pois seu espaço físico não comporta a demanda de frequentadores diários, principalmente na época das festividades de Natal e Ano Novo.

Além da construção de novos galpões comerciais, a CEASA-GO deverá reestruturar seu espaço físico com uma melhor distribuição dos banheiros, implantação de corredores exclusivos de carrinhos de mão e empilhadeiras, e também exigir o cumprimento das normas de trânsito no interior da Central de Abastecimento para melhorar a circulação dentro do mercado.

\section{Considerações finais}

Neste trabalho, buscou-se dar o contexto atual da CEASA-GO, bem como sua evolução ao longo dos anos. Fica bastante claro o papel de destaque que tem essa Central de Abastecimento, não só quando comparada às demais CEASAS do Brasil, mas também em relação ao município de Goiânia, ao estado de Goiás e à região Centro-Oeste. Nesse sentido, acredita-se que é de grande valia um estudo que esclareça o papel da instituição e sugira alterações viáveis e benéficas.

Procurou-se, também, de forma crítica e analítica, por meio da pesquisa realizada, refletir sobre o perfil socioeconômico e a visão dos agentes privados e públicos frente à gestão e ao planejamento da Central de Abastecimento de Goiás. A realidade encontrada foi surpreendente, superando expectativas e demonstrando resultados pertinentes aos temas pesquisados.

A premissa básica deste estudo foi a de identificar os problemas referentes à gestão e à infraestrutura da Central de Abastecimento de Goiás na visão de seus agentes, os quais compartilharam a mesma opinião, ou seja, que a CEASA-GO está no limite de sua capacidade para atender às novas e complexas exigências dos mercados. 


\section{Referências}

ALMEIDA, M.; FREITAS, C. R.; SOUZA, I. M. Gestão do conhecimento para tomada de decisão. São Paulo: Atlas, 2011.

BAUER, M. W.; GASKELL, G. Pesquisa qualitativa com texto, imagem e som: um manual prático. 2. ed. Petrópolis: Vozes, 2002, 516p.

CENTRAL DE ABASTECIMENTO DO ESTADO DE GOIÁS S/A - CEASA-GO. Disponível em: <http://www.ceasa.goias.gov.br>. Acesso em: 1 jun. de 2017.

. Relatório do Banco de Alimentos da CEASA-GO. Goiânia. Centrais de Abastecimento de Goiás. Informações concedidas em 2015.

. Relatório técnico 2014, CDI Comunidade CEASA/UNIAP. Goiânia, 2014.

. Relatório técnico 2015, CDI Comunidade CEASA/UNIAP. Goiânia, 2015.

COMPANHIA NACIONAL DE ABASTECIMENTO. Relatório do Programa Brasileiro de Modernização do Mercado Hortigranjeiro (PROHORT): período 2011/2015. Disponível em:

<http://dw.prohort.conab.gov.br/pentaho/Prohort>. Acesso em: 18 jun. 2017.

CUNHA, A. R. A. A.; BELIK, W. Abastecimento no Brasil: o desafio de alimentar as cidades e promover o Desenvolvimento rural. In: GRISA, C.; SCHNEIDER, S. (Orgs.): Políticas públicas de desenvolvimento rural no Brasil. Porto Alegre: UFRGS, 2015. p. 217-235 (Série Estudos Rurais).

CUNHA, A.; BISMARCK, J. C.; ALMEIDA, G. O Sistema Brasileiro de Centrais de Abastecimento e os mercados de Quarta Geração. 49 Encontro da SOBER - Sociedade Brasileira de Economia, Administração e Sociologia Rural. Belo Horizonte, 24 a 27 de jul. 2011.

CURY, A. Organização e Métodos: uma visão holística. 8. ed. rev. e amp. São Paulo: Atlas, 2012.

KUMAGAI, O. T. Entrevista concedida a Karla Kellem de Lima. Goiânia, 29 dez. 2014.

LIMA, K. K. Pesquisa realizada na Central de Abastecimento do Estado de Goiás. Goiânia:

CEASA-GO. 2014/2015

LOPES, J. C. Entrevista concedida a Karla Kellem de Lima. Goiânia, 20 out. 2014.

MATIAS-PEREIRA, J. Manual de Gestão Pública Contemporânea. 4. ed. São Paulo: Atlas, 2012.

MOURÃO, I. R. A.; MAGALHÃES, J. S. B. Breve História do Mercado Atacadista de Hortigranjeiros no Brasil. In: Manual Operacional das Ceasas do Brasil. ABRACEN, Belo Horizonte: AD2, 2011. p. 18-34.

MOURÃO, I. R. A. Manual I: Breve História do Sistema de Ceasas no Brasil (1960 a 2007). Fev. de 2008. Disponível em: <http://www.ceasa.gov.br/pub43>. Acesso em: 24 nov. 2011.

PEREIRA, S. A. R. Função Social das CEASAS. In: Manual Operacional das Ceasas do Brasil. ABRACEN, Belo Horizonte: AD2, 2011. p. 229-233.

ROBBINS, S. P.; JUDGE, T. A.; SOBRAL, F. Comportamento Organizacional: teoria e prática no contexto brasileiro. São Paulo: Pearson Prentice Hall, 2010. 
SILVA, L. I. Área de ocupação e produção de cana-de-açúcar no Estado de Goiás e o processo de substituição em relação às outras culturas alimentares (2003 a 2012). 2015. 70 p. Dissertação (Mestrado em Desenvolvimento e Planejamento Territorial) - Pontifícia Universidade Católica de Goiás, Goiânia, 2015.

SIQUEIRA, J. L. Entrevista concedida a Karla Kellem de Lima. Goiânia, 12 março 2015.

UNIAP. UNIÃO DOS ATACADISTAS E PRODUTORES DE HORTIFRUTIGRANJEIROS DO ESTADO DE GOIÁS. Material concedido pela Diretoria Executiva da UNIAP. Acesso em: 26 de ago. 2013.

VEIGA JÚNIOR, W. G.; ROSA, E. P.; SILVA, T. Estrutura técnica de uma Central de Abastecimento. In: Manual Operacional das Ceasas do Brasil. ABRACEN, Belo Horizonte: AD2, 2011. p. 47-54.

VERGARA, S. C. Projetos e Relatórios de Pesquisa em Administração. 8. ed. São Paulo: Atlas, 2007. ZEITUNE, C. R. Conceito das Ceasas. In: Manual Operacional das Ceasas do Brasil. ABRACEN, Belo Horizonte: AD2, 2011. p. 9-13. 